\title{
LAME SCIENCE? BLIND RELIGION?
}

\author{
by Holmes Rolston, III
}

\begin{abstract}
In Consecrating Science, Lisa Sideris argues that an anthropocentric and science-based cosmology encourages human arrogance and diminishes a sense of wonder in human experience immersed in the natural world, as found in diverse cultural and religious traditions. I agree with her that science elevated to a commanding worldview, scientism, is a common and contemporary mistake, to be deplored, a lame science. But I further argue that science has introduced us to the marvels of deep nature and vastly increased our human appreciation of nature as a wonderland at levels great and small. Sideris is right to fear consecrating science. She-and the humanists, sages, and saviors - need also to fear blindness to what science has to teach us about cosmogenesis and wonderland Earth.
\end{abstract}

Keywords: cosmogenesis; Lisa Sideris; wonder; wonderland Earth

Lisa Sideris is right on target in her doubts about "creeping scientism," what she calls "mythopoetic science," or Consecrating Science (Sideris 2017, $1,3)$. She welcomes scientists open to wonder; Rachel Carson is her role model. She distrusts scientists who insist that an appropriate worldview must appropriate science as both necessary and sufficient to any legitimate cosmology, superior to humanistic or religious views. "Proponents of this new cosmology see cutting-edge scientific knowledge as the primary vehicle for restoring enchantment, wonder, meaning, and value to the natural world ... a grand narrative of cosmogenesis." Such "epic science"

Holmes Rolston, III, is University Distinguished Professor and Professor of Philosophy Emeritus at Colorado State University, Fort Collins, CO, USA; e-mail: holmes.rolston@ colostate.edu 
(Sideris 2017, 1, 4) displaces our personal, phenomenal wonder in sensory encounter with nature-rainbows, thunderstorms, warbler calls, fall colors, a residential landscape we love, such as the Shenandoah Valley, or the wild Grand Canyon at sunset with its dramatic colors and vast abyss, the sense of mystery, sacred nature, and the supernatural.

Albert Einstein once remarked: "Science without religion is lame, religion without science is blind" (Einstein 1956, 24). I agree that science without religion is lame, in the sense that science is unable to make the deepest value judgments about life in the cosmos, about the meaning of life. But I think some religious prophets and wise men can "see" what scientists cannot. I worried whether religion without science is blind.

I think now that Einstein meant that our five senses (sight, hearing, taste, smell, and touch) are impressive, and enable us to get around quite well in the everyday world - to enjoy those fall colors and sunsets. But unaided by scientific instruments and discoveries, we are blind to most of what is going on. Science enables us to appreciate the universe and world we live in vastly more than common personal experience, vastly more than humanists, prophets, or religious sages.

Scientists have thought up theories and built detection instruments that have enabled humans to understand nature at multiple levels-from tiny quarks to super-sized galaxies. We know how to measure distances from picometers (one trillionth of a meter) to the extent of the visible universe in light years-about ninety-three billion light years (Bars and Terning 2010, 27).

The distance differences from picometers to the size of the known universe range across forty orders of magnitude. We measure the strengths of the four major binding forces in nature (gravity, electromagnetism, the strong and weak nuclear forces) again across forty orders of magnitude. We measure time at ranges across thirty-four orders of magnitude, from attoseconds to the billions-of-years age of the universe.

Without science, we would not know that humans evolved out of fossil stardust, in a cosmos creatively generated out of a fluctuation in a quantum vacuum. We would not know the five-billion year history of life on the Earth-from microbes to dinosaurs to mammals, through perhaps fivebillion species. Humans find themselves uniquely emplaced on a unique planet-in their world cognitively and critically as no other species is. Our bodily incarnation embeds us in this biospheric community; we are Earthlings. On the Earth, humans are, by all accounts, the most complex and startling species.

Our mental genius enables us to rise to transcending overview. So we can conclude that on this wonderland Earth we Homo sapiens are the wonder of wonders. Humans are endowed with a genetic heritage producing the human mind, by far the most complex thing known, of virtually infinite complexity, capable of semantic and symbolic speech. With such mind, 
humans generate cumulative transmissible cultures, elaborating high orders of rational and emotional thought in science, philosophy, ethics, and religious faith.

Humans alone ask who they are, where they are, and what they ought to do. We can conclude that we are genius on top. Next, we have to wonder what that can mean-how can and ought we to be on top? "A proper scientific interpretation of evolution does not lead to an argument against God. Scientific atheism is a metaphysical position, which goes beyond a purely scientific interpretation of the available scientific evidence. Science does not imply atheism, does not endorse atheism" (Nowak 2014, 51).

Such science has introduced us to the marvels of deep nature, and vastly increased our human appreciation of nature as a wonderland at levels great and small, across forty orders of magnitude. Science finds humans in the middle of these levels, a wonder of wonders with their minds and sensory and religious experiences-yet blind to most of what is going on without science. In that sense, a science-based worldview is demanded of everyone who wishes to know what is really taking place.

Sideris is right to fear consecrating science. She-and the humanists, sages, and saviors - need also to fear blindness to what science has to teach us about cosmogenesis and wonderland Earth.

\section{ACKNOWLEDGMENT}

A version of this article was previously presented as part of a Zygon Journal panel at the Annual Meeting of the American Academy of Religion (AAR) in Denver, Colorado, on November 17, 2018.

\section{REFERENCES}

Bars, Itzhak, and John Terning. 2010. Extra Dimensions in Space and Time. New York, NY: Springer.

Einstein, Albert. 1956. Out of My Later Years. New York, NY: Philosophical Library.

Nowak, Martin. 2014. "God and Evolution." In The Science and Religion Dialogue: Past and Future, edited by Michael Welker, 47-52. Frankfurt am Main, Germany: Peter Lang.

Sideris, Lisa H. 2017. Consecrating Science: Wonder, Knowledge, and the Natural World. Oakland: University of California Press. 